\title{
La guerra fría, la seguridad nacional y el Estado militar en Sudamérica $(1959-1980)^{*}$
}

\author{
The Cold War, National Security, \\ and the Military State in South America \\ (1959-1980)
}

\author{
Pedro Rivas Nieto** \\ (D) https://orcid.org/0000-0002-2829-7294 \\ Facultad de Ciencias Sociales y Jurídicas \\ Universidad Loyola Andalucía, España \\ privas@uloyola.es
}

\author{
Pablo Rey-García *** \\ (D) https://orcid.org/0000-0001-9962-7003 \\ Departamento de Humanidades \\ Universidad Pontificia de Salamanca, España \\ preyga@upsa.es
}

* Este artículo se liga con el proyecto de investigación titulado "Protección de las minorías frente a los discursos del odio", cuya referencia es DER2015-66189-P y fue financiado por el Ministerio de Economía y Competitividad del Gobierno de España.

** Doctor en Ciencias Sociales y de la Información, máster en Relaciones Internacionales. Líneas de investigación: guerra y terrorismo, asuntos militares, seguridad.

*** Doctor en Ciencias Sociales y de la Información, máster en Paz, Seguridad y Defensa, Diploma de Estudios Avanzados en Historia Contemporánea. Líneas de investigación: asuntos militares, terrorismo, imágenes de guerra.

cómo citar: Rivas Nieto, P., Rey-García, P. y McGowan, N. (2021). La guerra fría, la seguridad nacional y el Estado militar en Sudamérica (1959-1980). Secuencia (111), e1928. Dor: https://doi.org/10.18234/secuencia.v0i111.1928

c) 98

Esta obra está protegida bajo una Licencia Creative Commons Atribución-NoComercial 4.0 Internacional. 


\section{Nadia McGowan **** \\ (1) https://orcid.org/0000-0003-3584-4767 \\ Universidad Internacional de la Rioja, España \\ nadia.mcgowan@unir.net}

Resumen: Este artículo tiene como objetivo principal comprender el concepto y la experiencia de la guerra fría en Sudamérica en los años sesenta y setenta del siglo xx -dado que fue en el Cono Sur en donde se desarrollaron con más eficacia los regímenes llamados de Seguridad Nacional-y, al mismo tiempo, penetrar en el modo en que esos regímenes crearon un tipo de Estado de carácter netamente militar. Para este trabajo se ha inspeccionado documentación y fuentes orales en distintos lugares -Argentina, Chile, Colombia, Israel-, durante varios años, con fines diversos, ligados todos ellos al estudio del fenómeno militar y, tras el análisis de parte de esa información para este artículo, se concluye que, en la guerra total y permanente contra el comunismo, la autoridad del Estado militar, fundado en origen para proteger del autoritarismo a la sociedad civil, se volvió despótica y el Estado deificado, tiránico.

Palabras clave: guerra fría; bipolaridad; seguridad nacional; Estado militar; Sudamérica.

Abstract: The main aim of this paper is to understand the concept and experience of the cold war in South America in the 1960s and 1970s -in the Southern Cone the so-called National Security regimes were effectively developed-and, at the same time, to understand the way in which those regimes created a military State. Archives and oral sources have been researched in different places -Argentina, Chile, Colombia, Israel-for several years with different purposes, all of them linked to the study of the military phenomenon and, after the analysis, it is concluded that, in the total war against communism, the authority of the military state originally founded to protect civil society from authoritarianism, became despotic and tyrannical.

**** Doctora en Comunicación, Publicidad y Relaciones Públicas. Líneas de investigación: seguridad, comunicación pública, estética y tecnología. 
Key words: cold war; bipolarity; national security; military State; South America.

Recibido: 7 de enero de 2021 Aceptado: 6 de julio de 2021

Publicado: 12 de octubre de 2021

\section{INTRODUCCIÓN}

T a gran tesis geopolítica relacionada con la Doctrina de Seguridad NacioLnal fue la integración inevitable de América Latina en uno de los dos bloques antagónicos de la guerra fría. Tal y como decían algunos de los creadores de la Doctrina, Iberoamérica formó parte del Occidente por necesidad científicamente fundamentada (Moro, 1976, pp. 4-21). Si para los doctrinarios de la Seguridad Nacional, el Occidente había sido atacado por Oriente desde tiempos inmemoriales (Couto e Silva, 1967), la agresión en la guerra fría la representaba el comunismo (Osiris, 1969). Occidente era la base geográfica de los centros de poder, así como de la encarnación de la civilización, del régimen democrático, del capitalismo y del cristianismo; era un ideal, un propósito y un programa, y era preciso occidentalizar el mundo entero (Martins, 1986, p. 20). Esta rigidez llevó a que no se tuvieran en cuenta las transformaciones habidas en el campo socialista -como el enfrentamiento chino-soviético- porque se entendía que no modificaban la bipolaridad, y los cambios se interpretaban como tácticas del comunismo para lograr el dominio mundial. Iberoamérica se integraba en Occidente tanto por pertenecer geográficamente a él como por vocación, en una especie de Destino Manifiesto para Sudamérica.

En realidad, la Doctrina de Seguridad Nacional era más una cultura que una doctrina al uso (Rivas, 2008, pp. 35-59), aunque hubo un sistema bien estructurado de la Seguridad Nacional (Cardoso, 1985; O'Donnell, 1982, 1972) formulado de manera explícita en tres niveles (Celam, 1977, pp. 13-14): el nivel académico, relacionado con escuelas militares dedicadas de forma continua al estudio de la seguridad nacional y a la elaboración de una doctrina; el nivel que cabría denominar de la acción política; y el de la mentalidad general, marcado por la sospecha generalizada y continua. Estaba de forma permanente en algunos sectores de las Fuerzas Armadas y de los gobiernos, cuya muestra más clara era el rechazo a la participación popular en la vida 
pública, económica y cultural, la persecución de la crítica o el verticalismo estatal. Los tres niveles se relacionaban entre sí y formaron un sistema social que escapaba al control de sus creadores quienes, a veces, fueron los que se volvieron críticos y combativos con el sistema que habían ayudado -incluso de buena fe-a crear. El documento que recogía las reflexiones de un grupo de expertos encomendados para estudiar este asunto por el Secretariado General del Consejo Episcopal Latinoamericano, reunidos en Puerto Rico en septiembre de 1977, decía en claras palabras que:

un sistema social, como una doctrina, tiene su lógica interna, frecuentemente implacable, que aparece más fuerte que la voluntad de los individuos, llevados a hacer lo que no querían porque no hay ya posibilidad de limitar el dinamismo del sistema. Dentro de las Fuerzas Armadas muchos sufren porque sienten que fueron llevados a hacer lo que no querían $y$, a veces, exactamente lo contrario de lo que querían, en virtud de las fuerzas desencadenadas por las medidas tomadas en nombre de la seguridad nacional. [...] Se dan cuenta de la situación [...] a que fueron llevados por principios que no conocían bien en todas sus implicaciones sociales (Celam, 1977, p. 15).

Partiendo de estas premisas, cabe formular la principal hipótesis de este trabajo: la guerra fría fue distinta en Iberoamérica dada la aparición y desarrollo de los regímenes de Seguridad Nacional, desarrollados especialmente en el Cono Sur, una de cuyas singularidades fue el fortalecimiento de un tipo de Estado de carácter militar, que a su vez influyó en la Doctrina de Seguridad Nacional y en el desarrollo de la guerra fría. Esa es la hipótesis principal que planteamos y que intentaremos verificar en este trabajo. Aunque hay una bibliografía consolidada respecto a las relaciones de la guerra fría y la Doctrina de Seguridad Nacional -como ocurre con Pion-Berlin (1989), Velásquez Rivera (2002), o Calandra y Franco (2021), por citar a cuatro destacados especialistas- creemos conveniente ahondar humildemente en este aspecto. No se trata tanto de innovar en una faceta del conocimiento, sólida gracias a la labor de los historiadores, sino de fortalecerlo mediante el manejo de cierta bibliografía más ligada a las Fuerzas Armadas -segunda parte del artículo-y, por tanto, denostada o alabada, en virtud de las convicciones ideológicas, y de algunas fuentes de primera mano que, acaso, contribuyan a este trabajo. Por eso los objetivos de este artículo serán tratar de comprender el concepto y la experiencia de la guerra fría en Sudamérica en los años sesenta y setenta 
del siglo $\mathrm{xx}$-pues fue en el Cono Sur en donde se desarrollaron con más eficacia los regímenes de Seguridad Nacional-y penetrar en el modo en que los regímenes denominados de Seguridad Nacional robustecieron un tipo de Estado de carácter netamente militar, que a su vez los benefició en una relación causa-efecto.

Podría pensarse que la selección de los años objeto de estudio, de 1959 a 1980, tiene cierto carácter discrecional y que se debe a un motivo funcional. Al margen de las necesidades organizativas propias de cualquier trabajo académico y de sus limitaciones, creemos que en ese periodo se produjeron algunos hechos relevantes de la guerra fría para el continente americano, ya fuera porque ocurrieron en él, ya fuera porque le afectaron directamente: en 1959 triunfó la revolución cubana; en 1961 surgió un régimen socialista en el Caribe; en 1962 tuvo lugar la Crisis de los Misiles; en 1968, la Primavera de Praga; ese mismo año, la guerra de Vietnam cambió de rumbo y, en 1975, concluyó; en los años sesenta y setenta, Brasil, Bolivia, Argentina, Chile, Uruguay, Panamá y Ecuador tuvieron dictaduras militares en medio de la guerra fría; y a partir de 1980, año en que concluimos nuestro estudio, fue cuando comenzó la conocida "década perdida".

Hay otro factor más claro para esta selección temporal y es que, si uno de los objetivos del artículo es estudiar la creación de un Estado de carácter militar desde la Doctrina de Seguridad Nacional, conviene tener en cuenta que, a pesar de que los ejércitos en Latinoamérica se profesionalizaron desde 1920 y 1930 hasta 1960, fue entre 1960 y 1968 cuando se internacionalizaron, además de que fue a partir de los años sesenta cuando surgió en Iberoamérica el pretorianismo tipo dirigente (Perlmutter, 1982, pp. 123-161). Fue en ese tiempo cuando las instituciones militares crearon estructuras ejecutivas que hicieron valer tanto su modernización como su autonomía (Rouquié, 1989) y el militar se empezó a preocupar no sólo de la defensa exterior, sino de la seguridad interior y del desarrollo nacional (Stepan, 1973, pp. 47-65). Antes de la segunda guerra mundial las Fuerzas Armadas tenían asignadas funciones policiales -aunque no les agradara demasiado-, pero en los sesenta y en los setenta se comprometieron en la defensa del orden interior por convicciones ideológicas. En América Latina los militares constituyeron una clase dirigente (Anderson, 1967, p. 328), si bien a principios de los años sesenta y setenta los ejércitos iberoamericanos aún estaban ligados, por regla general, al tipo de régimen liberal que había existido en Europa en los siglos xix y xx. 
La reflexión y el análisis en este artículo se hacen esencialmente de dos formas: con el empleo de fuentes documentales de disciplinas diversas diseccionadas mediante trabajo hermenéutico y, en menor medida, fuentes orales. Dicho de otro modo: el trabajo nace de varias estancias de investigación y del examen metódico de documentos ligados con el estudio de la guerra fría, de la Doctrina de Seguridad Nacional y del Estado Militar en centros de investigación de países de América Latina y de Oriente Próximo, a saber: la Pontificia Universidad Católica (PUC) de Santiago en Chile, el Instituto de Investigaciones Gino Germani de la Facultad de Ciencias Sociales de la Universidad de Buenos Aires (UBA) en Argentina, la Universidad Pontificia Bolivariana (UPB) de Medellín, en Colombia, el Truman Institute for the Advancement of Peace de la Hebrew University de Jerusalén, y el Meir Amit Intelligence and Terrorism Center en Tel Aviv, ambos en Israel.

Para el análisis de las fuentes orales se empleó la técnica de entrevista no estructurada de elites (Manheim y Rich, 2002, p. 182), basada en la clásica focused interview de Merton, Fiske y Kendall (1946), en la que los investigadores seleccionan a expertos a quienes se interroga buscando categorías específicas de estudio. A diferencia de la encuesta de muestra representativa, no se entrevista aleatoriamente; y a diferencia de la habitual entrevista estructurada, se busca que el encuestado sea quien organice el relato de los hechos examinados. Para este estudio se entrevistó a personal civil y militar de diversa condición en Argentina, Chile, Colombia e Israel en un periodo prolongado -algunas entrevistas han estado en nuestros archivos personales durante casi 20 años- $y$ algunos de los nombres de los entrevistados se han ocultado bajo seudónimo por petición expresa del entrevistado.

Este trabajo se organiza de la siguiente manera: en primer lugar, está la introducción, en donde se plantea el problema que se quiere estudiar, los objetivos y cómo se organizará el conjunto del trabajo. En segundo lugar, se estudiarán los imperativos políticos de la guerra fría y el problema de la bipolaridad. En tercer lugar, se indagará en los orígenes, concepto y naturaleza de la guerra fría en Iberoamérica; para entender sus reglas del juego, se revisarán las contradicciones teórico-prácticas y, después, sus efectos en la región. En cuarto lugar, se investiga el carácter, organización y comportamiento de las Fuerzas Armadas en el Cono Sur en este periodo para deducir si es posible hablar, en quinto lugar, de la construcción de un Estado netamente militar. Por último, están las conclusiones del artículo. 


\section{BIPOLARIDAD Y GUERRA FRÍA: ACTORES E IMPERATIVOS POLÍTICOS}

Los doctrinarios de la Seguridad Nacional quisieron hacer de la geopolítica la base privilegiada del Estado y a aquella unieron la bipolaridad. Quizá el efecto más claro y directo de esta última es que rompía la clásica doctrina del equilibrio de poder deseada por los realistas políticos y por los viejos estadistas británicos y príncipes austriacos que les precedieron en la belicosa Europa.

Cabe decir, aunque a priori parezca contradictorio, que en el sistema bipolar hay tres tipos de actores, a saber: los jefes de las coaliciones, los Estados obligados a tomar partido y a adherirse a uno de los bandos, y los Estados que desean permanecer al margen del conflicto, porque pueden hacerlo (Aron, 1985, p. 183). Este sistema no es más propenso a la guerra ni más inestable que el pluripolar, pero sí está más amenazado por una guerra general que, en caso de que estalle, hace casi inevitable que se vuelva ideológica. Como escribió Aron (1985): "La paz será belicosa y la guerra fría cuando esta prohibición [la de reclutar clientelas partidistas en el interior de los Estados] no exista, aún antes de que se desencadene la lucha a muerte" (p. 187). Tucídides lo había dicho ya 2000 años antes en la Historia de la guerra del Peloponeso. El sistema de las ciudades griegas era bipolar y el de la segunda mitad del siglo xx también, pero un sistema que afectaba al planeta entero difería en su naturaleza del de la Antigüedad o del sistema de Estados europeos, porque los medios de destrucción de la URSS y de Estados Unidos cambiaban la esencia de la competencia diplomática y estratégica.

La división del mundo en dos campos, el "Occidente" y el "Comunismo", permitía que la disposición natural de quienes defendían la Doctrina de Seguridad Nacional fuera la de adherirse al primero. Los defensores de la Seguridad Nacional invocaban razones morales o históricas (Amaral, 1975) o incluso usaban el argumento de la subversión para adherirse a Occidente. Esta era una tesis sencilla y simplificada, pues postulaban que todos los movimientos guerrilleros, o todos los partidos de izquierda -o incluso los grupos que no lo eran, pero que, en su opinión, podrían llegar a serlo- estaban dirigidos desde Moscú. Era lógico este razonamiento si el comunismo, para estas gentes, era un movimiento de conspiración mundial para conquistar el poder y monopolizarlo en la época de decadencia capitalista. Burnham (1951) afirmaba que ambos sólo eran rivales "en el mismo sentido que lo son dos candidatos al campeonato de boxeo de pesos pesados” (p. 95) y mantenía que el comunismo 
oficial defendía el terror como una forma legítima de defensa contra los enemigos de clase. Además, disponía de la mayor organización propagandística que jamás hubiera existido y no era remiso a pactar con el enemigo -los países occidentales-, tal y como Stalin -el realista político supremo, según Kissinger (1996), "paciente, astuto e implacable, el Richelieu de su época" (p. 350)había demostrado, convencido de la victoria final (Leites, 1953, p. 501).

En los años setenta la bipolaridad se invocaba en Iberoamérica por los partidarios de la Doctrina de Seguridad Nacional con más frecuencia que en los años más duros de la guerra fría (Harmer, 2013). La visión estadunidense ortodoxa respecto a este fenómeno afirmaba que la guerra fría era la respuesta valiente de muchos hombres a la agresión comunista. Los geopolíticos partidarios de esta tesis la justificaban remontándose a las ambiciones de los zares que llevaron a la guerra de Crimea; a la intromisión rusa en los Balcanes, Oriente Próximo y Medio, y a las presiones sobre las zonas cercanas a las posesiones británicas en la India. Los ideólogos lo achacaban al Manifiesto Comunista; y otros estudiosos y hombres de Estado concluían que el paneslavismo ruso unido al mesianismo leninista se enfrentaron con Occidente al acabar la segunda guerra mundial para dominarlo (Neumann, 1967). En realidad, la rivalidad Este-Oeste era un hecho gigantesco que acababa imponiéndose por sí solo.

\section{LA GUERRA FRÍA EN IBEROAMÉRICA}

\section{Orígenes y naturaleza}

Schlesinger (1988, p. 179) escribe que la controversia sobre el origen de la guerra fría había causado una pequeña guerra fría entre los historiadores. La escuela de las Puertas Abiertas argüía que el imperialismo estadunidense causó la guerra fría y la escuela geopolítica sostenía que la guerra fría fue la responsable de que se fortaleciera el imperialismo de Estados Unidos. Para la teoría de las Puertas Abiertas, el imperialismo es siempre un vicio del capitalismo, por tanto, la URSS era inmune a él. Sin embargo, Jefferson creía que cuando el poder de Europa estaba en unas solas manos, Estados Unidos estaba en peligro. Y esto era una cuestión geopolítica. El equilibrio de poder moldeó el pensamiento de Roosevelt de la política exterior y por eso intentó integrar a la URSS en un nuevo orden político internacional (Gaddis, 1982, p. 13). Para los teóricos de la Doctrina de Seguridad Nacional la guerra contemporánea se 
presentaba bajo la forma de la guerra fría y, aunque hubiera cambiado sus formas, había que responder de la manera adecuada. La Doctrina de Seguridad Nacional ${ }^{1}$ era, precisamente, una respuesta a ese tipo de guerra.

El punto de partida en América Latina fue la interpretación que se dio de la política soviética, en la que se aseguraba que el comunismo era una repetición del nacionalsocialismo -ambos eran expansionistas-y que la actuación soviética era una política de guerra que perseguía la conquista del mundo. $\mathrm{Si}$ su voluntad de guerra no se expresaba mediante acciones militares era porque se trataba de un nuevo tipo de guerra. La meta suprema de la guerra fría era el dominio completo del mundo y, para ello, intentaría utilizar medios no militares, aunque no renunciara a emplear ocasionalmente a los ejércitos. Por si fuera poco, los éxitos comunistas en la guerra fría podían también conducir a situaciones revolucionarias (Pereira, 1997, p. 13) y en la Gran Enciclopedia Soviética se definía, recuerda Pereira (1997), como "un rumbo político agresivo que tomaron los círculos reaccionarios de las potencias imperialistas, bajo la dirección de los EE. UU. e Inglaterra, a raíz de la Segunda Guerra Mundial. [...] Está orientada [...] a agudizar la tensión internacional, y a crear las condiciones para el desencadenamiento de una nueva guerra mundial" (p. 16).

\section{Reglas del juego}

Las dos grandes potencias que se enfrentaban en el mundo jugaban con reglas alejadas del tradicional sistema de equilibrio de poder que había mantenido segura a Europa durante casi dos siglos. Sólo Estados Unidos tenía los medios para organizar la defensa del mundo no comunista, en cierta visión caricaturesca que algunos sectores del país tenían del resto del mundo, que creían antiamericano y antidemocrático (Friedman, 2015). El Kremlin pensaba en las clásicas esferas de interés y en proteger sus fronteras, especialmente la occidental, pues la Madre Rusia fue atacada cuatro veces -invasión napoleónica, guerra de Crimea, la Gran Guerra y la segunda guerra mundial- en poco más de un siglo. Probablemente sus objetivos iniciales no eran tanto la

${ }^{1}$ Para una mejor comprensión del fenómeno de la Doctrina de Seguridad Nacional en la guerra fría sería adecuada una contextualización histórica y terminológica que permitiera una mejor aprehensión del proceso. No obstante, dadas las limitaciones de espacio de un artículo académico, y siendo un tema conocido entre los especialistas, nos permitimos cierta complicidad con el lector de esta publicación, del que suponemos tiene un conocimiento apriorístico del contexto. 
conquista del mundo como la seguridad rusa, habida cuenta de las obsesiones estalinistas en construir un glacis protector a lo largo de la frontera oriental rusa. En certeras palabras decía Schlesinger (1988) que "Stalin no era el prisionero indefenso de la ideología [...] Ya había corregido la historia rusa, y tenía el poder de corregir la doctrina comunista. En verdad, sólo Stalin podía revisar la doctrina, y la doctrina no revisada condenó a la Unión Soviética y a Estados Unidos a una enemistad permanente" (p. 215).

Mientras la URSS siguiese siendo un Estado mesiánico, la ideología la obligaba a una expansión constante del poder comunista. La Doctrina Truman de marzo de 1947 fue la que afirmó que la política de Estados Unidos debía consistir en apoyar a los pueblos libres que se resistieran a todos los intentos de dominarlos, ya fuera mediante minorías armadas o mediante presiones exteriores, con los problemas que la falta de matiz puede ocasionar para la libertad defendida y el bagaje experiencial que aporta para repetir esos excesos en el futuro (Grandin, 2006). Y fue tranquilizadora para Occidente, aunque los británicos dudaban de que pudiese dar algo más que ayuda económica, pues creían que no se comprometería en serio en la defensa de Europa occidental (Rothwell, 1982, p. 259).

Lo peor de esto es que la guerra fría y la Doctrina Truman proporcionaban una clave para interpretar todo lo que pudiera suceder en el mundo. Cada vez que en cualquier lugar del mundo se cuestionara el statu quo, se criticara agriamente al gobierno de Estados Unidos, o pudiera llegarse a hacerlo, había que ver la sombra de la guerra fría y, por ende, la mano de Moscú. La guerra fría era una realidad presente en todas partes, además de servir para explicar de forma simple todos los acontecimientos mundiales.

Cuando en virtud de este ideario Estados Unidos entró en la guerra de Vietnam, hasta los realistas políticos más conocidos, como Morgenthau, criticaron no la forma de hacer la guerra, sino la guerra misma (Podhoretz, 1982, p. 105). Al final de la guerra Estados Unifos falló en su tarea de contener el comunismo y la URSS intentó extenderse por África y Asia, pero también fracasó su deseo de dominio permanente (Gleijeses, 2013).

\section{Contradicciones}

Pero la historia de la guerra fría era la historia de las contradicciones entre la teoría y la práctica. Además, tuvo graves efectos desestabilizadores en América 
Latina, probablemente por el comportamiento estadunidense y por la propia agenda de los Estados latinoamericanos (Darnton, 2014). Desde el siglo XIX Estados Unidos había intentado que Latinoamérica diera seguridad al flanco sur del país (Jordan y Taylor, 1981, p. 436), pero en el periodo que atañe a este trabajo la derecha más dura se adhirió sin fisuras a la línea estadunidense -la obra coordinada por Field, Krepp y Pettinà (2020) es buena muestra de ello-, caracterizada por su furibundo anticomunismo, mientras que la izquierda - parte de ella antes afiliada a un panamericanismo partidario de la democracia social- se vio sin apoyo por parte de Estados Unidos (Veiga, Da Cal, Duarte, 1997, p. 165), especialmente en la transición de los tiempos de Truman a los de Eisenhower. La política conservadora de Estados Unidos en Iberoamérica se valió de dos instrumentos adoptados por la comunidad interamericana en 1947 y 1948: el Tratado Interamericano de Asistencia Recíproca (TIAR) y la Organización de los Estados Americanos (OEA). Estados Unidos posiblemente los veía como parte de su entramado anticomunista; si la Organización del Tratado del Atlántico Norte (otAN) los unía a Europa contra los soviéticos, el TIAR podía hacer lo mismo en América (Boersner, 1982, p. 255). Desde 1948 se colocó la seguridad militar y policial por encima de otros aspectos en Iberoamérica, lo cual, presumiblemente, hizo posible el derrocamiento de los gobiernos de Perú y de Venezuela en ese mismo año y el de Cuba en 1952. El influjo del macartismo se hizo notar en todo el continente. Y si hasta 1953 Estados Unidos toleraba rebeliones reformistas, el endurecimiento de la guerra fría los animó a respaldar denodadamente el antiizquierdismo, incluso el de carácter autoritario.

En Iberoamérica el concepto de guerra fría llegó a ser una ley, pues según la Doctrina de la Seguridad Nacional se estaba en guerra contra el comunismo internacional. La "distensión”, que desde la época de Kissinger al frente de la Secretaría de Estado era la doctrina oficial en la política exterior de Estados Unidos, no se tomó en serio en el Cono Sur. En 1973 el general Breno Borges Fortes decía en Montevideo que tenía la convicción de que "en lo que concierne a la seguridad de las Américas no ha habido cambios fundamentales [...]. Nuestro enemigo es siempre el movimiento comunista internacional que, en algunos casos, ha cambiado solo su estrategia de acción, pero sin renunciar a su objetivo final: la conquista del poder" (Comblin, 1979, p. 39). Esos años coinciden con cierto retroceso en América. A partir de 1973 se fortaleció el apoyo a los regímenes autoritarios. En Uruguay, en junio de 1973, Bordaberry dio un autogolpe en unión de los militares, disolvió el parla- 
mento, los sindicatos, los partidos políticos de izquierda y purgó las universidades de "elementos marxistas". La suspensión de garantías constitucionales y la gobernación mediante decretos de emergencia de los meses anteriores al golpe de Estado, pensados para acabar con la violencia de los Tupamaros, acabaron siendo permanentes. En Brasil, desde el golpe militar de 1964, los dictadores militares, aliados con Nixon y su asesor Kissinger, fueron férreos defensores del occidentalismo, pues las fronteras ya no eran territoriales, sino ideológicas y esto justificaba la contrainfiltración para golpear al enemigo infiltrado en un país vecino. Nixon decía que Brasil podía ser un modelo para el resto de Iberoamérica. Algo parecido ocurrió con los regímenes de Chile y de Argentina. En fin, todo un sistema de degradación democrática se instaló en el continente, aunque algunos países se esforzaran por mantener, más o menos, su carácter democrático, como México, Colombia, Venezuela o Ecuador. Boersner (1982) dice que "el ámbito de las democracias, semidemocracias y "dictablandas" de Latinoamérica septentrional y del Caribe, no obstante sus contradicciones y divergencias internas [...] mantuvo pues, entre 1973 y 1976, una indudable coherencia fundamental, haciendo contrapeso a la tendencia de la parte meridional y oriental de Sudamérica, hacia el retroceso represivo" (p. 333). Con la llegada de Carter al poder en Estados Unidos en 1977, y hasta su salida en 1981, la defensa de los derechos humanos pareció marcar la política exterior del país, debilitados a partir de inicios de los años ochenta de nuevo en el continente.

\section{Efectos de la guerra fría en Iberoamérica}

Para los defensores de la Doctrina de Seguridad Nacional, de la guerra fría se obtenía la idea de una guerra omnipresente en donde todo conflicto debía interpretarse como actividad de guerra del enemigo -el comunismo internacional-. Además, la ideología del sistema era una respuesta a la "inconsciencia" de los pueblos iberoamericanos, pues parecía que desde los tiempos de la independencia de la metrópoli habían estado en guerra permanente, en constante revolución, y el ejemplo más claro y peligroso de aquella tendencia era el triunfo de la revolución cubana en 1959. El triunfo de los barbudos, quienes se habían alzado en armas contra el régimen de Batista en pos de una verdadera democracia (Meneses, 1995, p. 63), había acabado en 1961 con la proclamación de una república socialista. Esta tendencia se había extendido a velocidad de 
vértigo por el continente. Los partidarios de la Doctrina de Seguridad Nacional querían mostrar a los iberoamericanos el estado de guerra que define la condición humana y prepararlos para actuar en consecuencia. En agosto de 1976, el -aún- coronel chileno Bacigalupo, de la Academia Superior de Seguridad Nacional, afirmaba que para muchos resultaba difícil admitir que el mundo estaba viviendo en una situación de guerra permanente (Bacigalupo, 1976, p. 37).

En el programa enunciado en el discurso que el general Pinochet dio el 11 de septiembre de 1973, día del golpe de Estado en Chile, toda su argumentación se basaba en la guerra abierta entre Chile y el comunismo. Lo nacional se fundía con lo global en esta lógica (Riquelme, 2014, pp. 21-32) y la década de los setenta era difícil en Hispanoamérica debido a la aparición de grupos insurgentes y contrainsurgentes en todo el continente, y aún iba a serlo más, sobre todo tras el triunfo de la revolución sandinista en Nicaragua en 1979 y la aparición de la segunda ola guerrillera. En noviembre de 1976, Morales, un oficial encargado del servicio de comunicaciones sociales del gobierno chileno, enviaba una circular a todas las instituciones nacionales para recordar a la nación que "el mundo actual está en guerra. El imperialismo soviético extiende cada vez más su dominación mediante una guerra de conquista que usa todas las formas conocidas de agresión moral, espiritual y física” (p. 1). ${ }^{2} Y$ era tan peligroso porque su Dios -la dialéctica histórica-era santificado e identificado con los fines últimos de la vida (Niebuhr, 1958, pp. 298-299). Era un enemigo con el que, por primera vez en la historia, no había nada en común.

Opiniones similares se mostraban en Iberoamérica en todos los países que aplicaban la Doctrina de Seguridad Nacional. En octubre de 1975, el jefe del Estado Mayor del Ejército de Tierra del Brasil, el general Fritz de Azevedo Manso, aseguraba que el mundo estaba en guerra y que esa guerra era total e impuesta por el comunismo. Su naturaleza expansionista, tal y como había asegurado Kennan, obligaba a frenarlo allá en donde la libertad estuviera amenazada en una suerte de contención permanente. La URSS, que había heredado la lógica expansionista de los zares, no podía más que crecer. Judt (2006) recoge unas palabras de Stalin, dichas cuando la segunda guerra mundial estaba a punto de llegar a su fin: "esta guerra no es como otras pasadas;

${ }^{2}$ Circular titulada Seguridad Nacional, firmada por Morales R. G., oficial de Estado Mayor (R), s. f., enviada en 1976. Archivo de la Vicaría de la Solidaridad, Arzobispado de Santiago, Chile. 
el que ocupa un territorio también impone su propio sistema social. Todo el mundo impone su propio sistema hasta allí donde su ejército le permite llegar. No puede ser de otro modo" (p. 201).

\section{LAS FUERZAS ARMADAS EN IBEROAMÉRICA}

Para ahondar en esta cuestión hay que recordar que los ejércitos en Latinoamérica se profesionalizaron desde 1920 y 1930 hasta 1960 y se internacionalizaron entre 1960 y 1968, durante la guerra fría y la hegemonía estadunidense. Antes de la segunda guerra mundial tenían también asignadas funciones de gendarmería, y no eran paladines de la democracia. Incluso constitucionalmente, en los países sudamericanos, la adaptación de los modelos europeos no excluía el ejercicio de responsabilidad política o de poder policial en épocas de agitación interna. Si los ejércitos alemán y francés en el siglo xx no eran apolíticos (Stevenson, 2013, p. 239), los sudamericanos que se entrenaron en Europa asimilaron una sensibilidad política moderna que no era prodemocrática (Nnun, 2004, pp. 174-175). Además, tras la segunda guerra mundial y la aparición de la guerra fría, los militares influidos por Estados Unidos fueron hostiles a todo aquello -ya fuera ideológico, cultural, económico o político- que pudiera amenazar la existencia de las Fuerzas Armadas al amenazar la del Estado (Nnun, 2004, p. 191).

A partir de los años sesenta surgió en Iberoamérica el pretorianismo tipo dirigente (Perlmutter, 1982, pp. 17-19, 123-161) y en ese tiempo las instituciones militares crearon estructuras ejecutivas que hicieron valer tanto su modernización como su autonomía. El militar se empezó a preocupar no sólo de la defensa exterior, sino de la seguridad interior y del desarrollo ${ }^{3}$ nacional (Stepan, 1973, pp. 47-65). Si antes de la segunda guerra mundial las Fuerzas Armadas tenían asignadas funciones policiales -aunque no les agradara

${ }^{3}$ El autoritarismo militar y el golpismo de este periodo tiene un fuerte componente económico que, aunque no es el objeto directo de este artículo, debe mencionarse por mor de la precisión. En el camino al desarrollo de la región frecuentemente tenía más peso el PIB y cualquier otro vector económico, que los peligros que el marxismo, por sí solo, pudiese suponer para los países, como O’Donnell $(1982,1972)$ demostró en sus estudios sobre el Estado burocrático-autoritario. El control del movimiento obrero tenía que ver con lo ideológico, claro está, pero también con la protección del sistema productivo para evitar desviacionismos. Probablemente se produjo más en el Cono Sur que en América Central, cuyos regímenes fueron más toscos. 
demasiado- en los sesenta y en los setenta se comprometían en la defensa del orden interior por convicciones ideológicas. Los militares iberoamericanos durante un siglo aportaron ideología, organización y administración a sus países y contribuyeron a desarrollar el Estado moderno, a pesar de que con frecuencia habían interpretado la democracia como control extranjero e ideología divisionaria de la sociedad, a la que aquella dañaba al primar en exceso los derechos individuales (Nnun, 2004, p. 193) En realidad, en América Latina los militares constituyeron una clase dirigente (Anderson, 1967, p. 328) y a principios de los años sesenta y setenta los ejércitos iberoamericanos aún estaban ligados, por regla general, al tipo de régimen liberal que había existido en Europa en los siglos xIx y xx. Cierto es que a partir de entonces se abandonó ese modelo a favor de un régimen pretoriano tipo dirigente, como firma Perlmutter (1982):

Cuando la autonomía corporativa se ligó con fortuna a la seguridad nacional (interior y exterior), se produjo un ejército pretoriano tipo dirigente que fue conservador en lo social aun cuando se comprometiera en la acción social. El oficial dirigente estaba inspirado por su formación y tendencia corporativa, y excepto en el caso de los políticos oportunistas (del tipo de Perón), constituyó una fuerza contra-revolucionaria. Hacia 1976 el clásico ejército tipo árbitro ya no existía como movilizador político (p. 273).

El poder político de la institución, tradicionalmente considerable, aumentó y se mezcló con el corporativismo, el autoritarismo de los regímenes y la revolución modernizadora, además del intento de frenar el comunismo y el izquierdismo interno. No en vano la tradición autoritaria existente en los regímenes militares se liga con el pretorianismo corporativo desarrollado en Iberoamérica durante más de un siglo (Perlmutter, 1982, p. 274).

Este carácter militar del Estado se fortalecía con el entrenamiento militar en Estados Unidos, que suponía tanto la preparación militar como la instrucción no militar. El entrenamiento era la adquisición de habilidades para tareas específicas y la instrucción era la adquisición de conocimientos para la carrera militar en general (Lang, 1964, p. 50). Se formaba a los oficiales porque eran la parte más influyente de las Fuerzas Armadas y eran ellos los que condicionaban demasiado la conducta de las Fuerzas Armadas (Gutteridge, 1965, p. 84). Hasta la segunda guerra mundial el entrenamiento de los países iberoamericanos lo hacía especialmente Alemania y su influjo autoritario 
fue notable (Case, 1970, p. 336). Después de esta guerra, la Ley de Defensa Mutua de 1951 disponía la ayuda para Iberoamérica, pero no decía nada de entrenamiento en Estados Unidos, y en 1954 se destinaron los fondos para que los oficiales latinoamericanos pudieran estudiar en Estados Unidos. El coronel Critz decía (Case, 1970, p. 337) que los métodos del programa consistían en entrenar a gente en Estados Unidos y en lugares del extranjero; en mantener equipos móviles de entrenamiento destacados en distintos países; en establecer técnicos estadunidenses en el extranjero; en visitar a los jefes superiores del extranjero para darles orientación, y en contar con personal estadunidense destacado en países extranjeros. A partir de 1963 disminuyó en Estados Unidos el interés porque se dieron cuenta de que el equipo suministrado por ellos y el entrenamiento se usaban con fines antidemocráticos, y el Parlamento pidió que se estudiara de nuevo el plan de entrenamiento. Además, la Alianza para el Progreso de Kennedy de 1961, considerada como expresión de solidaridad interamericana en lo económico y en lo social para que Iberoamérica evolucionara de esa forma -y que parecía más aceptable para conseguir la estabilidad en América Latina-, suponía una alternativa al Programa de Ayuda Militar. Si en 1956 dos tercios de los programas de ayuda eran militares, en 1966 sólo un tercio era militar y dos tercios eran económicos. Pese a esto, a partir de 1962, las fuerzas aéreas entrenaron a los ejércitos latinoamericanos en tácticas de guerrillas y contraguerrillas y el ejército destinó equipos móviles de especialistas en entrenamiento antiguerrillero. ¿Por qué?, porque la amenaza de una invasión exterior dejaba de ser la preocupación fundamental y la prioridad era la creación de una fuerza interna de seguridad interior en América Latina. El temor a la subversión interna -a la guerra revolucionaria (Rivas y Rey, 2019, pp. 60-69)-inspiró esto. No en vano, en este contexto de guerra fría, la oEA describía la revolución como ajena a la tradición latinoamericana por su vínculo con la Unión Soviética (Marchesi, 2019, p. 82). Después de la segunda guerra mundial y hasta 1960 el Programa de Ayuda Militar para América Latina estaba pensado para enfrentarse a una amenaza exterior. En 1960 empezó a cambiar al pensarse que el enemigo era interno. Y en 1961 en Fort Gulick, en la zona del Canal de Panamá, comenzó el primer curso de contrarresistencia.

Debido a esta formación, a la tradición intervencionista y a las evoluciones posteriores, los militares podían gobernar sus países. Debían hacerlo ellos -los militares quienes, dentro de las Fuerzas Armadas, impusieron el camino de la Seguridad Nacional- porque las virtudes de su clase -valor, 
incorruptibilidad, desinterés..., según pensaban de sí mismos- representaban la contrapartida de los vicios destructores de la nación y porque estaban por encima de los partidos, y fuera de ellos. No debe olvidarse que las Fuerzas Armadas modernas tienen rasgos fundamentales insoslayables, como alta organización y coherencia, mando centralizado, autoridad organizada de forma piramidal, autoridad despersonalizada, estratificación interna fuerte y bien visible, disciplina y énfasis en el "debido canal", fácil comunicación interna, espíritu de cuerpo, cierto aislamiento respecto a la sociedad, ${ }^{4}$ actividad de tiempo completo, burocratización, normas propias, ${ }^{5}$ previsiones financieras permanentes, estatus social diferencial, corporatividad y responsabilidad profesional (Ochoa y Beltrán, 1968, pp. 18-20) Todo esto ocurre tanto en tiempo de guerra como en tiempo de paz. Y estas características las marcan, para bien y para mal. Y las distinguen de la sociedad civil, menos

${ }^{4}$ Entrevista al señor Yoram Kahati, exagente de inteligencia y académico, realizada por Pablo Rey, Nadia McGowan y Pedro Rivas, Tel Aviv, Israel, julio de 2019. En este punto de la investigación cabe aclarar que se añadirán testimonios recogidos en entrevistas hechas en diferentes países y en diferentes momentos. Se pueden sintetizar en tres los momentos, junto con tres perfiles de entrevistados, en dos continentes distintos. Un primer momento responde a entrevistas hechas en Argentina y Chile como fase previa para la redacción de un libro y de varios artículos sobre la Doctrina de Seguridad Nacional. Un segundo momento responde a entrevistas hechas en Colombia para estudiar la acción militar contra guerrillas específicas del Cono Sur. Un tercer momento responde a entrevistas hechas en Israel para estudiar el accionar y el razonamiento militar, tanto general como específico, contra grupos armados de Oriente Próximo. De esos tres niveles, aparentemente alejados entre sí, se pueden extraer ideas interesantes para este trabajo, porque responden a investigaciones en las que los objetos de estudio son complementarios, a saber: razones y comportamiento de las Fuerzas Armadas en la lucha antisubversiva. Por eso, las razones aducidas pueden resultar complementarias y aclaratorias en este trabajo, a pesar de que se hicieran en diferentes tiempos y lugares.

Los tres perfiles de entrevistados son los siguientes: militares y agentes de inteligencia que han tenido responsabilidades directas en la búsqueda de insurgentes; políticos y diplomáticos con experiencia de campo; $y$ académicos especializados en estas cuestiones, parte de los cuales fueron represaliados -en Argentina y en Chile- por los regímenes militares. Hay también, en menor medida, activistas y defensores de derechos humanos -como la conocida Hebe de Bonafini-, aunque algunos de los académicos, políticos y diplomáticos tienen también esa faceta, por eso no la establecemos como categoría independiente.

Huelga decir que, por las habituales razones de limitación de espacio de una publicación académica, ha habido que reducir a la mínima expresión las respuestas y los contenidos de las entrevistas, y eso puede suponer cierta falta de contexto, que el conocimiento del lector de una publicación académica como Secuencia completa.

${ }^{5}$ Entrevista al señor Rodolfo Richter, exoficial de las Fuerzas Armadas argentinas, realizada por Pedro Rivas, Buenos Aires, Argentina, septiembre de 2009. 
organizada. ${ }^{6}$ La misma división de poderes del orden civil, en que también hay mando, hace que el poder civil sea heterogéneo. Por eso parecían los más capaces para fortalecer el Estado.

Téngase además en cuenta que, en las modernas ideas de la Defensa Nacional, incluso en el mundo democrático, esta no se limitaba sólo a la defensa física del territorio, sino a la defensa de lo permanente, de los valores de la patria, cuya salvaguardia se configuraba en el ejército. ${ }^{7}$ La defensa también es la del mantenimiento y robustecimiento de las ideas que proporcionan la subsistencia del Estado (Oehling, 1967, p. 63) y si la guerra no era solamente cosa de militares -incluso en el mundo democrático occidental y europeo, tal y como reconoció ya en 1948 el ministro de Defensa francés, Ramadier (Les aspects civils e militaires de la Défense Nationale, 1958, p. 207)-, la defensa nacional llegaba -y llega- más allá del empleo de las armas. Toda esta visión amplificada se daba en la Doctrina de la Seguridad Nacional, pues si el fin de todo ejército es la victoria (Jouvenel, 1957, p. 269) contra el ataque extranjero, también su fin es frenar la subversión interior. Hacia el exterior defiende al país de invasiones, y en el interior de desórdenes y violencia que pongan en un aprieto la subsistencia de los ciudadanos y del orden. ${ }^{8}$ El ejército es una forma defensiva de la nación que actúa en el momento oportuno (Lasalle, 1957, p. 25). Cuando este cree que es superior en organización -tradición en Iberoamérica al estar más cercanos a los niveles europeos de la industria, por ejemplo, que otros cuerpos-, tiende a actuar. ${ }^{9}$ Las Fuerzas Armadas modernas estaban bien cohesionadas, actuaban unitariamente hacia objetivos prefijados y esto las distinguía de la sociedad civil, pero las situaba en el extremo opuesto de la sociedad civil en los países latinoamericanos.

Por eso, a veces, en Hispanoamérica se había auspiciado el situar a un militar en las altas magistraturas del Estado como la fórmula más adecuada

${ }^{6}$ Entrevista al señor Marco Ibarra (seudónimo), oficial de las Fuerzas Armadas colombianas, realizada por Pedro Rivas, Bogotá, Colombia, julio de 2012.

${ }^{7}$ Entrevista al señor Rodolfo Richter, exoficial de las Fuerzas Armadas argentinas, realizada por Pedro Rivas, Buenos Aires, Argentina, septiembre de 2009. "Y eso que no siempre los jefes -en la vida militar, en la guerrillera, o en la civil- son capaces de dirigir a la tropa”, afirma Richter.

${ }^{8}$ Entrevista al señor Víctor Vázquez (seudónimo), oficial de las Fuerzas Armadas colombianas, realizada por Pedro Rivas, Bogotá, Colombia, julio de 2012.

${ }_{9}$ Entrevista al señor Yoram Kahati, exagente de inteligencia y académico, realizada por Pablo Rey, Nadia McGowan, Pedro Rivas, Tel Aviv, Israel, julio de 2019. 
para impedir la intervención política de los militares, ${ }^{10}$ lo cual en el fondo quería asegurar la más legítima estabilidad política y así actualizaban cuestiones bastante viejas, ya planteadas por Aristóteles. El hecho de que un militar ocupara la jefatura del Estado no suponía de suyo que la ocupara un militar, si estaba en ella como simple ciudadano. Ya Aristóteles se preguntaba si las funciones militares y las políticas debían ser confiadas a las mismas personas o a gentes distintas. Y respondía de forma ambigua a diferentes personas en la medida en que unas funciones necesitan fortaleza y, las otras, sabiduría; pero ambas a la misma persona para prevenir alteraciones políticas de origen militar. Nunca ha sido fácil que quienes pueden usar la fuerza la limiten voluntariamente, porque los que llevan armas pueden siempre determinar el sino de la constitución (Lozada, 1967, p. 19). Además, como se estaba en estado de guerra, no creían que un gobierno civil tuviera la energía necesaria para enfrentarse a los desafíos de la seguridad nacional y del desarrollo. ${ }^{11}$ Contrario a Von Clausewitz, pensaban que la conducción política de la guerra correspondía a los generales, pues debían de ser quienes pusieran en práctica la estrategia, los que hicieran la política.

${ }^{10}$ Entrevista al señor Carlos Floria, exembajador argentino ante la UNESCO y académico, realizada por Pedro Rivas, Buenos Aires, Argentina, septiembre de 2009.

${ }^{11}$ Merece la pena ampliar brevemente lo del desarrollo, porque cuando Santiago de Chile se convirtió en el centro de producción de las ciencias sociales de América del Sur (Marchesi, 2019, p. 120) y los Cuadernos del Centro de Estudios Socioeconómicos de la Universidad de Chile, editados entre 1966 y 1968, tuvieron gran influencia en los ámbitos académicos, adquirió preponderancia la idea de André Gunder Frank de que en Latinoamérica la burguesía no iba a emancipar a la economía, ni al pueblo, del subdesarrollo (Frank, 1970, p. 158). Halperin Dongui (1982, p. 1) dice que la obra de Frank, aunque por poco tiempo, se acogió con agrado en Estados Unidos y en América Latina, pues proporcionaba la base económica y social que completaba las conclusiones políticas de Régis Debray. Estas tesis económicas afirmaban, grosso modo, que la radicalización política en América Latina era inevitable, pues la única salida del capitalismo para subsistir en la crisis económica y política de Latinoamérica era el fascismo -diferente del europeo-, determinado por los procesos de transnacionalización económica. Solo había, entonces, dos salidas: el socialismo o el fascismo (Marchesi, 2019, p. 125). La explotación en el continente y el carácter de la burguesía ofrecían nuevas justificaciones para la continentalidad de la revolución en este periodo de guerra fría, y contra eso pretendieron "reaccionar" los regímenes militares. Al respecto, ciertas tesis aducidas por Loveman (2001) sobre los vectores económicos del Chile de la dictadura de Pinochet, claro ejemplo de régimen militar preocupado por lo económico, son aclaratorias. 


\section{LA CONSTRUCCIÓN DEL ESTADO MILITAR}

Un elemento interesante de los Estados de Seguridad Nacional era que, además de su autoritarismo burocrático autoritario (O’Donnell, 1982), adquiría preponderancia lo militar. El paso del Estado autoritario al Estado militar era relativamente simple. ${ }^{12}$ Por regla general la política iberoamericana había estado marcada por la inestabilidad en las formas de gobierno hasta los años sesenta (Alcántara, 1991, pp. 126-143). Se había combinado el trasfondo del constitucionalismo decimonónico liberal con la preponderancia del presidencialismo y, a la vez, cierta tendencia a emplear medidas de fuerza. Así que desde los años sesenta llegó la experiencia autoritaria, cuyo primer paso era el elitismo radical del sistema.

En Iberoamérica -creían los partidarios de la Doctrina de Seguridad Nacional- lo más granado solamente podía encontrarse entre los militares bajo la razón falaz de que la sociedad civil era homogénea. ${ }^{13}$ ¿Por qué?, por la traición de los civiles -quienes habían creado el problema de la supervivencia de la nación- y por la radicalidad de la guerra, que requería una dirección militar. Los civiles no sólo habían hecho malos gobiernos, sino que habían corrompido a la nación, la habían destruido o habían dejado actuar al desorden, a tal punto que era necesario rehacerla por completo. Por esta razón la simple intervención de las Fuerzas Armadas para reemplazar un mal gobierno por uno bueno -el pronunciamiento clásico- no era suficiente, sobre todo si había clara intención de dominarlo todo para destruirlo todo ${ }^{14}$ aunque era un medio necesario para hacerse con el poder. Si la patria estaba en peligro había que reconstruirla en su integridad y no sólo regenerarla. Por eso sólo podían emprender esta tarea los militares, aunque quizá debían hacerlo junto con la burguesía, porque ella era aliada natural de las Fuerzas Armadas. ${ }^{15}$ En la Declaración de Principios de la Junta Militar Chilena (1974), la cual se dio a

${ }^{12}$ Entrevista a la señora Inés Izaguirre, académica, realizada por Pedro Rivas, Buenos Aires, Argentina, septiembre de 2009.

${ }^{13}$ Entrevista al señor Emilio Crenzel, académico, realizada por Pedro Rivas, Buenos Aires, Argentina, septiembre de 2009.

${ }^{14}$ Entrevista a la señora Hebe de Bonafini, activista, realizada por Pedro Rivas, Buenos Aires, Argentina, septiembre de 2009.

${ }^{15}$ Entrevista a la señora Inés Izaguirre, académica, realizada por Pedro Rivas, Buenos Aires, Argentina, septiembre de 2009. No obstante, pese a estos razonamientos de los militares, "no se entiende toda esta organización compleja sin la intención de implantar un modelo económico de corte neoliberal, de Escuela de Chicago, contra el que no pocos militares eran 
conocer en los días posteriores al golpe de Estado del 11 de septiembre de 1973, se decía que la Junta asumía "las tareas de reconstruir moralmente, institucionalmente y materialmente el país [...] en definitiva existe el deber imperioso de cambiar la mentalidad de los chilenos" (pp. 28 y ss.) ${ }^{16}$ Afirmaba Jorge Uribe, ligado de forma profesional y personal al presidente Salvador Allende de Chile que, en estas situaciones, se generaba un perverso vínculo entre la posibilidad de hacer política y la de morir. ${ }^{17}$

Por eso no es correcto decir que los regímenes de Seguridad Nacional se caracterizaban por el caudillismo, o que las intervenciones militares que tuvieron lugar antes de su advenimiento fueron actos propios de caudillos. ${ }^{18}$ El militarismo implica el empleo de las armas, pero proviene de un sector del cuerpo de oficiales. No se trata de una intervención personal y popular, sino de una colectividad organizada y disciplinada que recurre a las armas en situaciones concretas. Es, quizá, un fenómeno sociopatológico que supone la invasión de lo militar y de su organización en la vida política y social de una sociedad (Watts, 1967, pp. 13 y ss.). Los regímenes de Seguridad Nacional no fueron el producto de los actos de caudillos libertadores, civiles, guerreros o militares, dotados de un singular carisma personal y coraje (Cuesta y De Arce, 2001, pp. 186 y ss.), con formas específicas de ejercer el poder, reclutar a sus hombres, practicar el clientelismo y populistas en su forma de entender la política (Safford, 1991, pp. 63-64). Esos regímenes fueron algo distinto, más elaborado. Eran las Fuerzas Armadas, cuya importante presencia en la historia del continente es indiscutible y que a sí mismas se tenían por la flor y nata de sus países, las que tomaban el poder. El problema estriba en que "esta militarización desmedida pensada para salvar a la nación" necesariamente hace que uno se parezca al enemigo. ${ }^{19}$

Los ejércitos, cuyas tradiciones se remontaban a los tiempos de la independencia, se tenían en casi toda Iberoamérica por fundadores, en cierta

contrarios". Entrevista a la señora Mónica González, periodista, realizada por Pedro Rivas, Santiago de Chile, Chile, septiembre de 2002.

${ }^{16}$ Véase Declaración de Principios de la Junta Militar Chilena, 1974. Archivo Documental del Instituto Libertad y Desarrollo, Las Condes, Santiago de Chile, Chile.

${ }^{17}$ Entrevista al señor Jorge Uribe, exsubdirector de la OIR durante la presidencia de Salvador Allende y académico, realizada por Pedro Rivas, Santiago de Chile, Chile, septiembre de 2002.

${ }^{18}$ Entrevista al señor Augusto Huidobro (seudónimo), diplomático, realizada por Pedro Rivas, Santiago de Chile, Chile, septiembre de 2002.

${ }_{19}^{19}$ Entrevista al señor Carlos Floria, exembajador argentino ante la unEsco y académico, realizada por Pedro Rivas, Buenos Aires, Argentina, septiembre de 2009. 
medida, de sus repúblicas (Rial, 1990, p. 2), y creían que a ellos les competía salvar a la patria. Al fin y al cabo, la misión de los ejércitos es de servicio civil, es decir, de servicio a la sociedad política (Dabin, 1955, p. 165), y desde 1920 hasta 1975 triunfaron 90 golpes de Estado en los 20 países de América Latina (Cuesta y De Arce, 2001, p. 186). En 1977 había gobiernos militares en una docena de países y en la mayoría se habían logrado mediante golpes de Estado (Germain, 1977, p. 69). Es verdad que desde finales de los años setenta comenzó un periodo de transición política a la democracia en América Latina y se abandonó el intervencionismo militar, pero Iglesia (1973) escribía que América Latina no era una región militarista con excepciones, sino una región cuyo sur atravesaba una etapa decididamente militarista "en parte por el influjo de factores específicamente militares, en parte porque el sistema de partidos ha dejado un hueco que otras fuerzas y, especialmente, los militares, tienden a llenar" (p. 87), mientras el norte se encaminaba a la consolidación de sus instituciones civiles.

No obstante, es absurdo pensar que la forma habitual que tenía el ejército de manifestarse en la vida pública y en la política era el golpismo. Eran -y son- muchas las formas que tenía de hacerlo y, con frecuencia, los ciudadanos las confundían. ${ }^{20}$

\section{CONCLUSIONES}

Probablemente la guerra fría fue algo distinta en Iberoamérica en el periodo que ocupa este trabajo, debido a la aparición de los regímenes de Seguridad Nacional, desarrollados especialmente en el Cono Sur, una de cuyas singularidades fue el fortalecimiento de un tipo de Estado de carácter militar que influyó en la Doctrina de Seguridad Nacional y en el desarrollo de la guerra fría. Esto se debió a que la bipolaridad ahondaba en la idea de que América Latina debía integrarse en el bloque capitalista por razones morales y por la necesidad de enfrentarse a la subversión comunista. Iberoamérica debía seguir la senda marcada por Estados Unidos. Y por comunismo se entendía lo que pusiera en entredicho cualquier aspecto del mundo occidental. La paralo mismo.

${ }^{20}$ El motín, el cuartelazo, la insurrección, el putsch, el pronunciamiento o el golpe no son 
noia anticomunista y el temor extremo eran los elementos fundamentales que unificaban la Doctrina de Seguridad Nacional.

Para los doctrinarios de la Seguridad Nacional el mundo de la época estaba en guerra permanente por culpa del comunismo. Y la idea de guerra total se había desarrollado sobre conceptos de carácter estrictamente político y militar, como los de guerra generalizada, guerra fría y guerra revolucionaria, parte todos ellos del concepto mayor de guerra, que marcaba la historia humana. Debía suprimirse la disidencia interna y esto obligaba a que todos los ciudadanos tuvieran la obligación de adherirse a los valores y principios de la nación, ya que toda ella debía involucrarse en la guerra contra el comunismo.

Esto ocurría en plena guerra fría, que era el nuevo rostro de la guerra total, en la que se luchaba en todos los frentes posibles. Era el enfrentamiento entre el bien y el mal, sin paliativos. Se pensaba que el comunismo, al igual que lo había sido el nacionalsocialismo, era expansionista y aspiraba al dominio del mundo. Por eso, gracias a la guerra fría, podía interpretarse cualquier hecho que ocurriera en cualquier lugar del mundo de forma simple y directa. La mano de Moscú estaba detrás de cualquier asunto que afectara a Occidente y, por ende, a América Latina, cuyas contradicciones eran resultado de ladinas manipulaciones. En realidad, más que el comunismo, fue la Doctrina de Seguridad Nacional la que, quizá sin prever sus consecuencias, dañó a un puñado de naciones.

Todo esto fue posible porque se desarrolló el concepto de Estado militar, el cual, aun no siendo patrimonio exclusivo de los regímenes inspirados por la Doctrina de Seguridad Nacional, sí era uno de sus elementos clave. La Doctrina de Seguridad Nacional, casi sin pretenderlo, instauraba un nuevo tipo de régimen político fuertemente autoritario que anulaba la participación popular y la restringía casi en exclusiva a los miembros de las Fuerzas Armadas partidarios de la Seguridad Nacional y a sus acólitos. El elitismo del sistema era la consecuencia y, a la vez, la causa de todo ello.

La regeneración de un país, desde esta lógica, sólo podían llevarla a cabo las Fuerzas Armadas, formadas por los más aptos, que no eran caciques ni caudillos al viejo estilo, pues intervenían en la política tomando el poder y organizando la sociedad según criterios militares. No en vano en los años setenta el Cono Sur atravesaba un periodo militarista que degradaba las instituciones civiles, ya bien desarrolladas al norte del continente.

La intervención en la vida política de las naciones no siempre la hacían por iniciativa propia, sino a veces a instancias de parte de la población civil, 
la cual confiaba en sus virtudes. Los ejércitos latinoamericanos eran profesionales y eficaces, y en los años de la aparición de estos regímenes de Seguridad Nacional habían abandonado los regímenes de tipo liberal europeo para ejercer cierto pretorianismo dirigente y contrarrevolucionario preocupado por frenar cualquier cosa que sonara a comunismo o a revolución. Como se suponía que los militares estaban al margen de las disputas partidistas e ideológicas, se suponía que su acción en política sería eficaz, favorecida por las características propias de las Fuerzas Armadas, como mando centralizado y autoridad piramidal.

El resultado de todo esto sólo podía ser un Estado militarizado, sin espacio para las divergencias, dogmático y convencido de que el hombre y la sociedad formaban un todo indisoluble. La autoridad de este Estado era ilimitada y su despotismo estaba obsesionado con imponer la uniformidad en los asuntos humanos. Bien pudiera ser que no hubiera un solo tipo de Estado militar, pues cabría pensar en subtipos con singularidades nacionales -el régimen chileno o el argentino no eran idénticos, por ejemplo-. No obstante, El Estado militar se deificó a sí mismo y se volvió tiránico, aun cuando acaso su intención fuera restaurar la autoridad perdida. Quiso ayudar a la sociedad civil y acabó dañándola con su carácter autoritario.

\section{LISTA DE REFERENCIAS}

Alcántara, M. (1991). El problema de la democracia en América Latina. Revista de Occidente, 124, 126-143.

Amaral, J. A. (1975). Segurança e democracia. Río de Janeiro: José Olympio.

Anderson, Ch. (1967). Politics and economic change in Latin America. Princeton: Princeton University Press.

Aron, R. (1985). Paz y guerra entre las naciones. Madrid: Alianza Editorial.

Bacigalupo, E. (1976). El Estado y la Seguridad Nacional. Seguridad Nacional, 1, 32-39.

Boersner, D. (1982). Relaciones internacionales de América Latina. Caracas-San José: Editorial Nueva Sociedad.

Burnham, J. (1951). La lucha por el imperio mundial. Madrid: Ediciones Pegaso.

Calandra, B. y Franco, M. (eds.) (2012). La guerra fría cultural en América Latina. Desafíos y límites para una nueva mirada de las relaciones interamericanas. Buenos Aires: Biblos. 
Cardoso, F. H. (1985). Caracterización de los regímenes autoritarios. En D. Collier (ed.), El nuevo autoritarismo en América Latina (pp. 39-62). México: FCE.

Case, R. (1970). El entrenamiento de militares latinoamericanos en los Estados Unidos. En V. R. Beltrán (ed.), El papel político y social de las Fuerzas Armadas en América Latina. Caracas: Monte Ávila Editores.

Comblin, J. (1979). La Doctrina de la Seguridad Nacional. Santiago de Chile: Arzobispado de Santiago/Vicaría de la Solidaridad.

Consejo Episcopal Latinoamericano (Celam) (1977). Doctrina de Seguridad Nacional. ¿Doctrina o ideología? Bogotá: Oficina de Prensa y Publicaciones Celam.

Couto e Silva, G. (1967). Geopolítica de Brasil. Río de Janeiro: José Olympio.

Cuesta, M. y De Arce, Á. (2001). Caudillos y militares como protagonistas del poder en Iberoamérica. En E. Martínez (coord.), Poder y mentalidad en España e Iberoamérica (pp. 181-204). Madrid: UCM.

Dabin, J. (1955). L’Etat ou Le Politique. París: Dalloz.

Darnton, C. (2014). Rivalry and alliance politics in cold war Latin America. Baltimore: Johns Hopkins University Press.

Iglesia, J. F. de la (1973). Breves anotaciones histórico-políticas sobre la intervención militar en América Latina. Bogotá: Facultad de Ciencias Jurídicas y Socioeconómicas-Universidad Javeriana.

Field, T., Krepp, S. y Pettinà, V. (eds.) (2020). Latin America and the global cold war. NC: University of North Carolina Press.

Frank, A. G. (1970). Capitalismo y subdesarrollo en América Latina. La Habana: Instituto del Libro.

Friedman, M. (2015). Repensando el antiamericanismo. Madrid: Antonio Machado Libros.

Gaddis, J. L. (1982). Strategies of containment: A critical appraisal of postwar American National Security. Nueva York: Oxford University Press.

Germain, L. (1977). La situación en América Latina. Revue de Etudes Polémologiques, 22, 35-51.

Gleijeses, P. (2013). Visions of freedom: Havana, Washington, Pretoria, and the Struggle for Southern Africa, 1976-1991. NC: University of North Carolina Press.

Grandin, G. (2006). Empire's workshop. Nueva York: Metropolitan.

Gutteridge, W. (1965). Military institutions and power in the new States. Nueva York: Frederick A. Praeger.

Halperin, T. (1982). Dependency theory and Latin American historiography. Latin American Research Review, 17(1), 115-130. 
Harmer, T. (2013). El gobierno de Allende y la guerra fría interamericana. Santiago de Chile: Ediciones UDP.

Jordan, A. y Taylor, W. J. (1981). American National Security: Policy and process. Baltimore: The John Hopkins University Press.

Jouvenel, B. (1957). La soberanía. Madrid: Rialp.

Judt, T. (2006). Postguerra. Una historia de Europa desde 1945. Madrid: Taurus.

Kissinger, H. (1996). Diplomacia. Barcelona: Ediciones B.

Lang, K. (1964). Technology and career management in the military establishment.

En M. Janowitz (ed.), The new military: Changing patterns of organizations (pp. 39-82). Nueva York: Russell Sage Foundation.

Lasalle, F. (1957). Qué es una Constitución. Buenos Aires: Ediciones Siglo Veinte.

Leites, N. (1953). A study of Bolchevism. Glencoe, Illinois: Free Press of Glencoe.

Les aspects civils et militaires de la Défense Nationale (1958). París: Institute de Études Juridiques-Université de Aix-Marseille-Puf.

Loveman, B. (2001). Chile, the legacy of hispanic capitalism. Nueva York: Oxford University Press.

Lozada, S. (1967). Las Fuerzas Armadas en la política hispanoamericana. Buenos Aires: Editorial Columba.

Manheim, J. y Rich, R. (2002). Empirical political analysis. Research methods in political science. Nueva York: Longham.

Marchesi, A. (2019). Hacer la revolución. Buenos Aires: Siglo XXI.

Martins, R. (1986). A Segurança Nacional. São Paulo: Editora Brasiliense.

Meneses, E. (1995). Castro: comienza la revolución. Madrid: Espasa-Calpe.

Merton, R., Fiske, M. y Kendall, P. (1946). The focused interview: a manual of problems and procedures. Glencoe: Free Press.

Moro, R. (1976). Historia de un expansionismo geopolítico. Geopolítica, 3/4, 27-41.

Neumann, W. L. (1967). After victory: Churchill, Roosevelt, Stalin and the Making of the Peace. Nueva York: Evanston.

Niebuhr, R. (1958). La ironía en la historia americana. Madrid: Instituto de Estudios Políticos.

Nnun, F. (2004). Las instituciones militares en transición: tiempos cambiantes y tiempos de cambio en el pensamiento y autopercepción de los cuerpos de oficiales en Latinoamérica. En Á. Soto y A. San Francisco (eds.), Estudios sobre América Latina en el cambio de siglo. Santiago de Chile: Ejército de Chile.

Ochoa, J. y Beltrán, V. R. (1968). Las Fuerzas Armadas hablan. Buenos Aires: Paidós. O’Donnell, G. (1972). Modernización y autoritarismo. Buenos Aires: Paidós. 
O’Donnell, G. (1982). 1966-1973. El Estado burocrático autoritario. Triunfos, derrotas y crisis. Buenos Aires: Editorial Belgrano.

Oehling, H. (1967). La función política del ejército. Madrid: Instituto de Estudios Políticos.

Osiris, G. (1969). Políticas y estrategias para el desarrollo y la seguridad nacional. Buenos Aires: Pleamar.

Pereira, J. C. (1997). Los orígenes de la guerra fría. Madrid: Arco Libros.

Perlmutter, A. (1982). Lo militar y lo político en el mundo moderno. Madrid: Ediciones Ejército.

Pion-Berlin, D. (1989). The ideology of state terror: Economic doctrine and political repression in Argentina and Peru. Boulder: Lynne Rienner Publishers.

Podhoretz, N. (1982). Why we were in Vietnam. Nueva York: Simon and Schuster.

Rial, J. (1990). Fuerzas Armadas y democracia. Los intereses de las corporaciones militares en América Latina. Montevideo: Peitho.

Riquelme, A. (2014). La guerra fría en Chile: los intrincados nexos entre lo nacional y lo global. En T. Harmer y A. Riquelme (eds.), Chile y la guerra fría global (pp. 21-32). Santiago de Chile: RIL Editores.

Rivas, P. (2008). Doctrina de Seguridad Nacional y regímenes militares en Iberoamérica. Alicante: Editorial Club Universitario.

Rivas, P. y Rey, P. (2019). Enseñanzas de la guerra revolucionaria y de la respuesta contrarrevolucionaria para la lucha antiterrorista. En M. Molina y R. González (eds.), Seguridad y defensa. Estrategias y desafíos en un mundo globalizado (pp. 59-78). Granada: Universidad de Granada-MADoc.

Rothwell, V. (1982). Britain and the cold war, 1941-1947. Londres: Cape.

Rouquié, A. (1989). The military and the State in Latin America. Berkeley: University of California Press.

Safford, F. (1991). Política, ideología y sociedad. En L. Bethell (ed.), Historia de América Latina, América Latina independiente: 1820-1870 (vol. vi, pp. 42-104). Barcelona: Crítica.

Schlesinger, A. (1988). Los ciclos de la historia americana. Madrid: Alianza Editorial.

Stepan, A. (1973). The new professionalism of internal warfare and military role expansion. En A. Stepan (ed.), Authoritarian Brazil (pp. 47-65). New Haven: Yale University Press.

Stevenson, D. (2013). 1914-1918, Historia de la primera guerra mundial. Barcelona: Debate.

Veiga, F., Da Cal, E. y Duarte, Á. (1997). La paz simulada. Madrid: Alianza Universidad. 
Velásquez Rivera, É. (2002). Historia de la Doctrina de Seguridad Nacional. Convergencia. Revista de Ciencias Sociales, 27, 11-39.

Watts, A. (1967). History of militarism. Nueva York: Mediam Book.

\section{OTRAS FUENTES}

\section{Archivos}

Archivo de la Vicaría de la Solidaridad, Arzobispado de Santiago, Chile.

Archivo Documental del Instituto Libertad y Desarrollo, Las Condes, Santiago de Chile, Chile. 